the scapula, its axillary edge differing considerably from the normal anatomy of that part. The most pro. minent feature of the scapula is the condition of the coracoid process. Instead of being the normal small

FIG. 1.

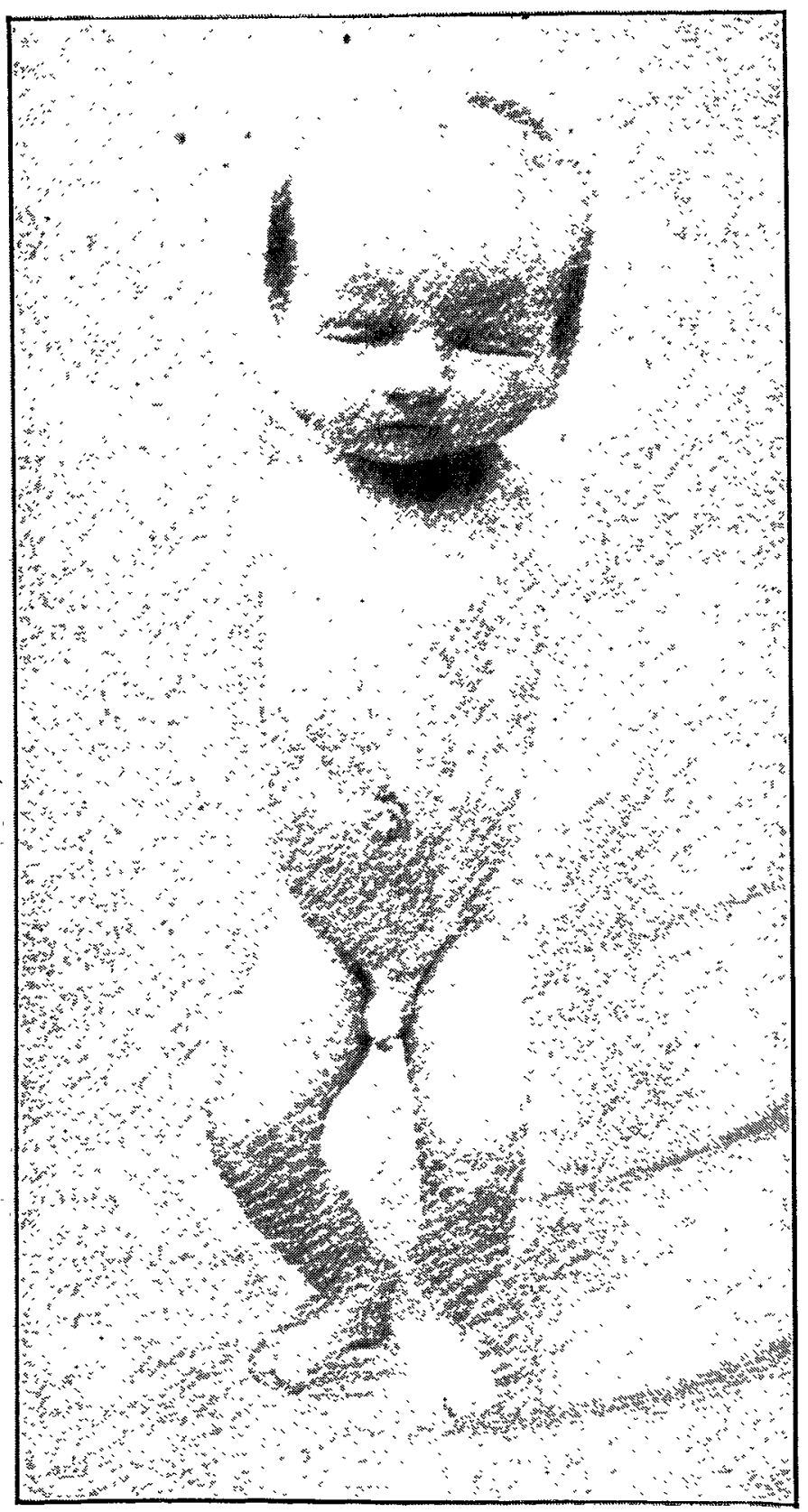

A case of congenital deficiency of the upper extremities.

FIG. 2.

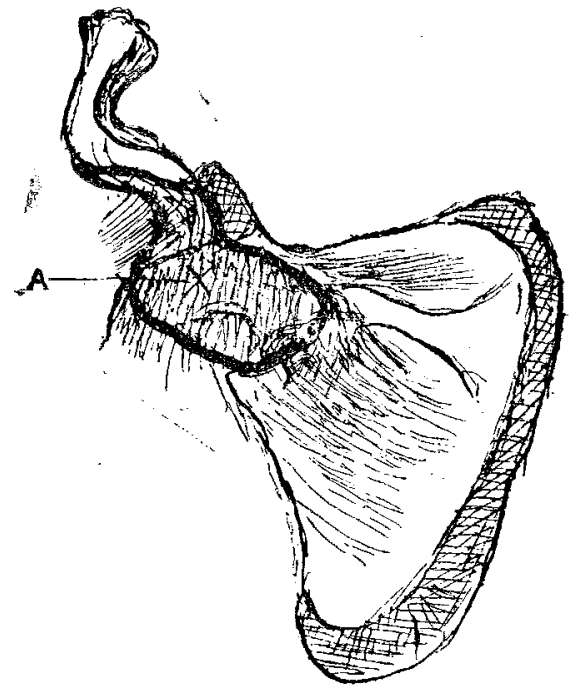

Diagram to show approximate area of aponeurosis. A, Aponeurosis. process, curved forward beneath and in front of the clavicle, it consists of one big process, being the continuation upwards of the body of the scapula. This extended behind, beneath, and above the clavicle, and there was a small articular surface between it and the clavicle. The tip of the process was capped with a large piece of articular cartilage. The size of this process, I presume, might be accounted for by the fact that owing to some error in development the cartilages of the glenoid cavity and the tip of the coracoid process had become fused into one common cartilage, possibly owing to some accidental jarring of the foetus in utero, but this could scarcely cause a symmetrical deformity. There is an attempt at a glenoid cavity at the axillary end of the base of the spine of the scapula in the shape of a small boss of bone with small articular surface placed inferiorly to the spine of the scapula. Its position can just be seen underneath the aponeurosis (A) in Fig. 2. The acromio-clavicular joint was quite normal but for a large amount of fibrous tissue forming the aponeurosis arising from it. There were no signs of a coracoacromial ligament. The biceps and all muscles which usually connect the two bones with the humerus appeared to be entirely absent.

I am greatly indebted to Mr. Thomas C. Pinny of Harlestone, Northampton, for the photograph illustrating the case. Burgess Hill.

\section{ON THREE CASES OF SUPRARENAL APOPLEXY IN CHILDREN.}

By FREDERIOK LANGMEAD, M.B. LoND., M.R.C.S. ENG, MEDICAI REGISTRAR TO THE HOSPITAL FOR SICK CHILDREN, GREAT ORMOND-STREET ; IAATE RESIDENT OBSTETRIC OFFICER, ST. MABY'S HOSPITAX.

THE possibility of almost sudden death in infants being due to hæmorrhage into the suprarenal capsules is so little recognised and so little is known about this disease that it seems worth while to record the following three cases with which I have come in contact.

OASE 1. - The patient was a baby, aged three days. The confinement was attended by St. Mary's Hospital Maternity Charity. He was a full term child and labour was easy. He never breathed freely ; he cried but not vigorously; however, he got a fairly good colour and death was not anticipated. On the morning of the third day the breathing became grunting in character and the child moaned and refused to take the breast. On the same evening he had a general convulsion, with loss of consciousness, became black in the face, blood ran from the nose and mouth, and he died in half an hour.

Post-mortem examination showed the child to be fairly well nourished. The neck, the head, and the face were covered with a purpuric eruption. The navel was quite sweet. There were no marks of violence. The internal organs were all normal with the exception of the lung and the suprarenal bodies. The right heart was distended. The lower lobe of the right lung contained a large hæmorrhage which had burst through the bronchioles and could be traced up into the trachea and larynx and was evidently the source of the blood seen externally. The suprarenal bodies were reddish-purple in colour and stood out against the posterior abdominal wall. They were equally implicated and were moderately distended with what proved to be on section recent blood extravasation. Hrmorrhage was confined to the suprarenals, the surrounding structures being unaffected. The family history was not relevant. The mother had had three other children; there had been no miscarriages and there was no family disease.

CASE 2.-The patient was a boy, an only child, two months old. He had been entirely breast-fed and had been perfectly healthy. He took the breast well and there had been no gastro-intestinal disturbance. On Feb. 29th, 1804, the mother fed him at 11 P.M. ; he took the breast and she noticed nothing wrong and afterwards he went to sleep. On the next morning at $5 \mathrm{~A} . \mathrm{M}$. the mother noticed a change; the child was breathing heavily. She said, however, that the colour was good, that there was no loss of consciousness, that the fists were not clenched, and that there were no squint, no sort of fit, and no screaming or apparent pain. The natural functions were performed normally. The mother could not get the child to suck. However, he went to sleep 
for about ten minutes and then woke again and again refused the breast. He was then redressed and two little reddish-purple spots were noticed over the buttocks and one on the neck. Others were looked for but none were seen. He was brought up hurriedly to St. Mary's Hospital but died on the way. I saw the child at 7 A.M., just after death. There was a purpuric eruption over the face, the chest, and the abdomen, and there were a few spots elsewhere. He was a plump baby and there was nothing in the throat to indicate the cause of death, nor were there any external marks of violence. No history of tubercle, syphilis, rheumatism, or hrmophilia in the family could be obtained. There was no infectious fever in the neighbourhood. The child had not been vaccinated.

Post mortem nothing abnormal was found except suprarenal hæmorrhage and purpura. The heart, the lungs, the brain, the kidneys, and the spleen were all healthy. The suprarenals were equally affected, were dark purple in colour, and appeared to be distended with blood though only slightly increased in bulk. The bæmorrhage had not encroached beyond the organs themselves. There was no thrombosis of the renal or inferior cava veins. On section the medulla was seen to be more deeply tinted than the cortex which was reddish in colour. Microscopically the capsule was stretched, with effusion of blood beneath it in places. The cortex was distinctly recognisable but contained a considerable number of red blood cells. In some places in the cortex the parenchymatous cells were entirely replaced by blood, in others there were just a few gland cells left, while in a very few spots the parenchyma was little changed. The cortical cells which remained seemed normal and took the stain well. The medulla was greatly dis. organised and showed marked necrotic change. The gland cells were indefinite in outline, swollen, and homogeneous, and took the stain badly; intermixing with them were many blood cells, greatly in the majority. The hæmorrhage into the medulla seemed to precede that of the cortex and here and there were clamps of brownish granules due to the breaking-down of hæmoglobin. There was no fatty change discernible and the blood-vessels were quite normal

For the notes of the third case I am indebted to Mr. A. F. Cole, late resident medical officer of the Mildmay Mission Hospital, Bethnal Green, and to Dr. W. Gauld, medical superintendent of the same institation, for permission to publish them.

CASE 3.-The patient was a girl, aged seven months, who previously had been quite healthy and who was taken to the Mildmay Mission Hospital on Feb. 14th, 1904, because she had awakened screaming at 3.30 that morning. The onset of an exanthem was suspected and the mother was told to take the child again if the rash appeared. The temperature was $99.2^{\circ} \mathrm{F}$. At 6 P.M. she was taken back again. The temperature was $104^{\circ}$ and she was covered with an intense purpuric eruption far thicker on the extremities than on the abdomen where the patches were further apart. The child was now distinctly ill, warranting the giving of a bad prognosis. She died on the next morning in a convulsion just $22 \frac{1}{2}$ hours after the initial screaming fit and 12 hours after the purpura had appeared. No history of small-pox, scarlet fever, measles, \&c., occurring in the neighbourhood could be obtained. She had been breastfed from birth and had had no drugging or patent food.

Post mortem the child was found to be an ordinary specimen, such as the neighbourhood produces, with no excess of fat on the body. Nothing abnormal anywhere was found except in the suprarenals. There was no bæmorrhage from the mucous or serous membranes. The suprarenals appeared as two masses of black blood clot, nearly half the size of the kidneys themselves, giving a remarkably vivid appearance on disturbing the intestines. Hæmorrhage was equally marked on both sides and was confined to the suprarenals.

The state of our ignorance of the etiology of suprarenal bæmorrhage is sufficiently exemplified by the number of theories which have been put forward. Spencer, ${ }^{\mathrm{I}}$ from examination of stillborn children, 20 per cent. of whom he found had suprarenal hæmorrhage, believed the prime factor to lie in the delicacy of the foetal blood-vessels in this organ either normally or as the result of syphilis. The additional strain necessary to cause rupture of the delicate bloodvessels he ascribed chiefly to mechanical squeezing by the

\footnotetext{
1 Transactions of the Orstetrical So iety of I on "on, 1891, vol. xxxiii
}

uterus during labour and to external violence, while he con sidered that asphyxia held a place of quite secondary importance. In support of this view he instanced his own cases, most of which succeeded difficult labour and especially breech births where manual interference is so often needed. Mattei ${ }^{2}$ considered that the large, heavy infantile liver was pressed back against the posterior abdominal wall during labour, squeezing the inferior vena cava against the vertebral column, and so damming back the blood into the suprarenals and causing it to burst its bounds. Against these theories is the tact that in many case a note has been made that labour was easy. Still, in 1898, from an analysis of 18 cases of hæmorrhage and congestion (the only ones he was able to collect), believed that while trauma and asphyxia would account for many of the cases in stillborn children and children dying within the first few days of birth, it was insufficient to explain those occurring later. After the fifth day he suggested that the cause might be found in fatty degeneration of the arterial walls. Others be believed to be due to a toxin. Hütinel ${ }^{4}$ advanced the theory that suprarenal hæmorrhages were preceded by thrombosis of the renal and inferior caval veins, into which the plexuses of the organ empty, resulting in consequent engorgement of these plexuses and subsequent rupture. Many anthorities believe this condition to be symptomatic of an acute specific fever, at any rate in the older infantr. Hamill ${ }^{5}$ was able to collect from various sources 90 cases of children in whom supra renal hæmorrhage or congestion occurred. These include 28 stillborn children, while some are merely pathological reports. From an exhaustive study of the literature of these cases and from careful analysis he apportioned them into three groups: (1) those in which death occurs during or before labour, due to manipulation and trauma; (2) those in which it occurs between birth and detachment of the cord, due chiefly to infection of the cord; and (3) those dying afterwards in which the cause is of an infectious or toxic nature. Of the 90 cases by far the greatest number belonged to the first group while only 11 came under the last heading.

There can be no doubt that while asphyzia and trauma can account for the great bulk of cases yet there is separable a small class, as pointed out by Eustace Talbot, ${ }^{\circ}$ for the explanation of which we must look farther afield. This group consists of cases of death occurring in older infants and is a very limited one. Talbot only reports four, to which he added two which came in his own experience. Into this group my last two cases fall. Those which come under this head are characterised by a very definite train of symptoms. A child previously well is suddenly seized with acute abdominal pain and vomiting and rapidly becomes seriously ill. The temperature rises and an exantbem is often suspected. No characteristic rash, however, appears although sometimes there is purpura. In a few cases there are other hæmorrhages resembling the "purpura fulminans" of Henoch, convulsions generally supervene, the patient becomes moribund, and death occurs in a period which may be counted by hours. It is to explain these cases that the toxæmic theory is called to our aid and seems most nearly to answer the question.

Firstly, there is a close resemblance between the clinical records of these cases and of those of acute specific diseases of a malignant type. Secondly, there is no lack of experi. mental evidence suggestive of a toxic orjgin. Gärtner isolated a bacillus like the colon bacillus, but not identical, which caused visceral hæmorrhage in dogs by intraperitoneal injection and recovered it from the animal's blood. Klebs and Eppinger ${ }^{8}$ isolated a micrococcus in cases of hæmorrhage into the viscera of children. Roux and Yersin ${ }^{9}$ caused con. gestion of the suprarenals by injection hypodermically of diphtheria bacilli into rabbits, guinea-pigs, and pigeons. Langlois. and Charrin ${ }^{10}$ produced engorgement of the suprarenals by injection of bacillus pyocyaneus. Pelliet ${ }^{11}$ obtained a like.

Lo Sperimentale, 1863, and Journal de Médecine, de Chirurgie, et de Pharmacologie de Bruxelles, 1865 .

3 Transactions of the Pathological Society of London, 1897-98, vol. xli. 
result by subcutaneous injection of essence of cloves into rabbits and guinea-pigs. Roger ${ }^{12}$ used a virulent culture of Friedländer's bacillus and produced in guinea-pigs engorgement and effusion into those glands. Talbot ${ }^{13}$ isolated from one case a streptococcus like pyogenes aureus but which differed from it in that it coagulated milk. Riesman ${ }^{14}$ found staphylococcus aureus and albus in pure culture from the blood and tissues of four cases.

Taking these data into consideration the possibility of a toxæmic origin becomes a probability but there are many difficulties. In the first place, it is surprising that in nearly every case in which bacteriological examination has been made the result proved negative. Then, again, in no case is there evidence of exposure to any source of infection, and furthermore, while profound toxæmia, the result of specific infection as in diphtheria and summer diarrhœa, is a common cause of death in children, cases of hæmorrhage into the suprarenals are very rare. If it be an infection presumably it is a special infection of unknown origin. I advance the crude state of our knowledge of this not unimportant condition as sufficient excuse for the publication of these additional cases.

London.

\section{FURTHER NOTE ON SOME ADDITIONAL POINTS IN CONNEXION WITH CHLOROFORMED CALF VACCINE. ${ }^{1}$}

\author{
By aLAN B. GReEN, M.A., M.D. Cantab. \\ (From the Government Lymph Laboratories.)
}

SINCE April, 1903, the date of my preliminary note ${ }^{2}$ on this subject, the preparation of calf vaccine by the chloroform process has been carried on at these laboratories and a large number of vaccines have now been treated by this method. These lymphs have been freed from their non-sporebearing extraneous bacteria within a period ranging between one and eight hours after their collection from the calf and have, subject to the usual tests, been issued for general vaccination purposes about two weeks after collection. Their use has resulted in high "case" and "insertion" success. The following points in connexion with these vaccines have been investigated.

The effect of temperature in the elimination of extraneous micro-organisms from orude calt vacoine by the chloroform process. - It has been ascertained that the temperature at which vaccine emulsion is subjected to the chloroform process determines largely the rate at which the extraneous bacteria of that emulsion are eliminated. This has been shown in two ways. In the first set of experiments vaccine emulsion consisting of one part by weight of pulp and two parts by weight of water was divided into several equal portions. Each portion was then submitted to a pre-determined and separate temperature along with the set of apparatus to be used for its treatment with chloroform. These temperatures ranged from $10^{\circ}$ to $37^{\circ} \mathrm{C}$. In each case after both emulsion and apparatus had reached the requisite tempezature of the experiment passage of chloroform vapour and air through the emulsion was effected. was found by means of plate cultivations that elimination of extraneous micro-organisms was most rapidly effected in the case of the emulsions chloroformed at $37^{\circ} \mathrm{C}$. and that elimination was most slowly effected in the case of the emulsions chloroformed at $10^{\circ} \mathrm{C}$. Between these temperatures the gradation of germicidal action was very constant. The potency of these vaccines was subsequently tested by inoculations on calves, with the result that vaccines which had been subjected to the chloroform process at temperatures below $30^{\circ} \mathrm{C}$. caused rather better vesiculation than the vaccines treated at temperatures above $30^{\circ} \mathrm{C}$. In the second set of experiments vaccine emulsion, prepared as before, was 12 Comptes Rendus des Séances de la Société de Biologie, January,
1894.

13 St. Bartholomew's Hospital Reports, 1900.

* Post-Mortem Reports, University Hospital, Philadelphia.

A paper read before the Royal Society on May 5th, 1904. Proceedings of the Royal Society, 1903, and THE LANCET,
June 20th, 1903, p. 1738 . divided into a number of equal portions, each of which was placed in a separate test-tube. In this case the emulsions were all subjected to the chloroform process at $15^{\circ} \mathrm{C}$. After the passage of chloroform vapour and air through the emulsions for half an hour, the entrance and exit of each vaccine tube were clamped in order that none of the contained chloroform might escape and the tubes were placed in temperatures ranging from $10^{\circ}$ to $37^{\circ} \mathrm{C}$. for 24 hours. In the case of these emulsions, where the amount of chloroform present in each must have been approximately the same, a similar gradation of germicidal action was evidenced as in the former set of experiments, elimination occurring most rapidly in the case of emulsions submitted to a temperature of $37^{\circ} \mathrm{C}$. and most slowly in the case of emulsions submitted to a temperature of $10^{\circ} \mathrm{C}$. The potency of each of these vaccine emulsions was tested as before by inoculations on calves, with the result that vaccines which had been submitted to temperatures below $30^{\circ} \mathrm{C}$. gave slightly better vesicles than vaccines which had been submitted to temperatures above $30^{\circ} \mathrm{C}$. Both series of experiments indicate that the temperatures at which extraneous bacteria are killed most quickly in vaccine emulsion by the chloroform process, the specific germ being left meanwhile in state of full activity, lie probably between $18^{\circ}$ and $23^{\circ} \mathrm{C}$

The species of micro-organisms lilled by the chloroform process. - In addition to the extraneous micro-organisms mentioned in the preliminary note as commonly occurring in crude calf vaccine and as being eliminated therefrom by means of chloroform experiments have been made with further species of bacteria. These, with the exception of the bacillus proteus valgaris and the bacillus coli communis, have never been found in vaccine lymph at these laboratories, but they have been subjected to the action of chloroform in order that knowledge of the germicidal value of that process might be extended. The bacteria thus experimented with are the bacillus proteus vulgaris, bacillus prodigiosus, bacillus pyocyaneus, bacillus flaorescens liquefaciens, bacillus coli communis, bacillus typhosus, bacillus diphtheriæ, bacillus mallei, bacillus pestis, bacillus tuberculosis, and spirillum choleræ Asiaticæ. Broth emulsions of these bacteria were first experimented with. As soon as an emulsion was established a suitable culture medium was inoculated with a small portion of it and duly incubated in order to ascertain whether the species of micro-organism in question could be easily recovered from the emulsion. The passage of chloroform vapour and air through the emnlsion was then begun and during the process at regular intervals further cultivations were made from it. In every instance the bacteria of experiment were found to have been killed at intervals ranging from one to eight hours from the commencement of the process. In a second set of experiments vaccine emulsions were prepared by mixing one part by weight of pulp with two parts by weight of water. To these emulsions the bacteria to be experimented with were added and cultivations were at once made therefrom in each instance to ascertain whether recovery of the bacteria was possible. Passage of chloroform vapour and air through the emulsions was then carried out and further cultivations were made from them from time to time. As in the case of the broth emulsions, after the passage of the chloroform vapour and air for a few hours the bacteria in the vaccine emulsions were killed. In the case of each experiment of the two foregoing series a "control " prepara. tion was established in which the bacteria were found to be still alive after the bacteria of the corresponding experimental preparation had been killed. The vaccine used in these experiments was collected for experimental purposes only

The keeping properties of chloroformed naccines.- The keeping properties of chloroformed vaccines have been tested in the following ways. First, vaccine lymph freshly collected from the calf was divided into two portions. One portion after emulsification with water was subjected to the chloroform process and after elimination of its extraneous micro-organisms the chloroform was partly removed by the passage through the emulsion of a stream of sterile air The other portion was emulsified with 50 per cent. of glycerine and water solution. These chloroformed and glycerinated emulsions were, within 24 hours of their collection from the calf, each subdivided into five parts, one part of each being stored at $10^{\circ}, 20^{\circ}, 25^{\circ}, 30^{\circ}$, and $37^{\circ} \mathrm{C}$. The potency of these several parts was subsequently tested on calves at regular intervals of time. The result showed (a) that the highest potency was retained for the longest time, alike for the chloroformed and glycerinated portions, by the 